\section{Health Services at the Primary Care Level}

Kameel Mungrue

Faculty of Medical Sciences, Department of Paraclinical Sciences, Public Health \& Primary Care Unit, The University of the West Indies, St. Augustine, Trinidad and Tobago

\section{Synonyms}

Principals; Value-system

\section{Introduction}

In June of 2014, the Port of Spain Municipal Cooperation celebrated 100 years as an institution. Part of its remit is maintaining the Public Health (PH) of the capital city as well as setting trends and exerting influence on the wider community. Its core activities are enshrined in the Public Health ordinance Chapter 12 No 4 of 1952, which exists to this day, unchanged. PH like all sciences must evolve with time as articulated by Rosen in 1958 (Rosen 1958), and as such this paper attempts to capture the achievements of the past 100 years PH practice in Trinidad.

\section{The Period 1914 -2015}

In 1914, Trinidad and Tobago (TTO) was a colony in the British Empire and therefore under colonial rule. Between 1914 and 1950, there was much turmoil; the world had experienced two world worlds and a global economic depression, which negatively impacted on social conditions and the delivery of health care. The labor riots of 1937 and the appointment of the West Indian Royal Commission in 1938, commonly known as the Moyne Commission, all impacted on health care in Trinidad.

One of the earliest challenges was the elimination of hookworm infestation. Through a system of chemotherapy, sanitation, the construction of pit latrines and health education during the period 1914-1925 hookworm was successfully eliminated as public problem (Tikasingh et al. 2011).

The next successful challenge was the eradication of the scourge of smallpox. TTO joined the smallpox eradication effort started by the World Health Organization in 1958 and by 1980 celebrated with the rest of the world in achieving the global eradication of smallpox. On 8 May 1980, during the eighth plenary meeting of the 33rd World Health Assembly, the president of the assembly, Al-Awadi, signed resolution WHA 33.3, which declared: "Having considered the development and results of the global programme on smallpox eradication initiated by WHO in 1958 and intensified since 1967 ... Declares solemnly that the world and its peoples have won 
freedom from smallpox" (World Health Organization 1980; Fenner et al. 1988). Three important factors contributed to this success: (1) the vaccine used that was a heat-stable, freeze-dried vaccine allowing long-term storage without refrigeration, (2) humans who are the only known reservoir for the virus, and (3) the cost of eradication and the high level of social and political commitment supporting the initiative.

In this period also, rabies, malaria, and tuberculosis also had to be confronted as well maintaining control of cholera. Although the last case of cholera occurred in the mid-1880s, continued vigilance was imperative. This surfaced in 1992 when cholera was reported in Venezuela, on 31 January 1992 (Pan American Health Organization 1991). Venezuela is only seven miles west of Trinidad, and there are frequent travel and trade between the countries, which created a real threat. A strategy of (1) intensifying the surveillance of diarrheal diseases, (2) strengthening the inspection of food offered for sale, and (3) providing public education and heightening public awareness, all basic PH strategies proved successful (Hospedalas and Holder 1993). Cholera did not occur in Trinidad and has not occurred in the past 100 years, which can be attributed to successful PH efforts. The first and only epidemic of rabies occurred between 1923 and 1937, which resulted in 86 deaths (Chadee et al. 1992). In this epidemic, Pawan in a seminal paper established through several experiments the transmission by bats (Chadee et al. 1999). Although malaria was successfully eradicated from Trinidad since 1964, several imported and autochthonous cases have been reported emphasizing the importance of malaria control (Mungrue 2010; Pawan 1936). Yellow fever (YF) has also significantly impacted on PH practice in Trinidad. Monath reported 15 cases in 1954 (Monath 1989). Although the last reported case was in 1979 primarily due to effective immunization strategies, Trinidad continues to experience only repeated epizootics of yellow fever virus (YFV). It is clear that YFV in Trinidad is maintained for relatively long periods, and Auguste and colleagues have hypothesized that epizootics emerge from viruses maintained in enzootic cycles. This however is contrary to observations of less synchronous epizootics in the Americas and raises the issue of what mechanisms could account for this. There is currently no definitive answer, but the mechanisms are likely to involve complex interactions among multiple factors (Auguste et al. 2010).

Tuberculosis (TB) has had a long and continuing PH impact in Trinidad. The first and only West Indian Inter-Colonial Tuberculosis Conference of 1913, "The tuberculosis Control Act (Ch 28:51)" of 1961, the discontinuation of BCG vaccine, the closure of the Cura sanitorium, and the arrival of HIV are only a few highlights of its impact. Consequently, it is beyond the scope of this study to address all the issues. Nevertheless after making huge efforts to control TD, in 2010, WHO reported that Trinidad and Tobago had the highest (30\%) prevalence of HIV among incident TB cases (i.e. 25 per 100,000 population in the Americas (Tuberculosis in the region of the Americas. Regional Report 2011).

While measles created an important challenge to $\mathrm{PH}$ in the 1980 s, there were significant epidemics of rubella also. One such epidemic in 1983 reported 1159 cases and 20 neonates delivered at the Mt. Hope Women's Hospital between November 1982 and July 1993 were diagnosed with congenital rubella syndrome (CRS) (Rosen 1958). The public health burden of rubella is related to the risk of infection in pregnant women. In 1991, Lewis and Potter reported that $46.4 \%$ of a sample of 1838 pregnant women were negative for rubella antibody, a surrogate indicator of the potential risk for CRS in a population (M. J. Lewis and I. Potter, Caribbean Epidemiology Center, unpublished data) (Orenstein et al. 1985). Thus, in 1988, the ministers of health of the Caribbean Community (CARICOM), a grouping of 13 independent states and six UK Caribbean overseas territories and Suriname, resolved to eradicate indigenous cases of measles from their countries, by means of mass vaccination targeting children 9-14 years. This resolution was implemented in May 1991. The measles, mumps, and rubella (MMR) vaccine (Schwarz strain of measles, Wistar RA-27/3M strain of rubella, Urabe strain of mumps) was used as it not only targeted measles but rubella and mumps. 
Health Services at the Primary Care Level, Table 1 Reported cases of measles, mumps, and rubella (1996-2004)

\begin{tabular}{l|l|l|l|l|l|l|l|l|l|l|l}
\hline & 1994 & 1995 & 1996 & 1997 & 1998 & 1999 & 2000 & 2001 & 2002 & 2003 & 2004 \\
\hline Measles & 1 & 26 & & 1 & - & - & 30 & 19 & 16 & 15 & - \\
\hline Mumps & 1 & - & & 3 & 4 & 1 & 650 & 603 & 515 & 464 & - \\
\hline Rubella & - & - & & 2 & 4 & 2 & - & 1 & - & - & - \\
\hline
\end{tabular}

Health Services at the Primary Care Level, Table 2 Reported cases of mumps for the period 2000-2003 by gender and age group 25-44 years

\begin{tabular}{l|l|l|l|l}
\hline & Males $n(\%)$ & Female $n(\%)$ & Age $(25-45)$ years $n(\%)$ & Total \\
\hline 2000 & $413(64)$ & $237(36)$ & $404(62)$ & 650 \\
\hline 2001 & $378(63)$ & $225(37)$ & $374(62)$ & 603 \\
\hline 2002 & $310(60)$ & $205(40)$ & $314(61)$ & 515 \\
\hline 2003 & $278(60)$ & $186(40)$ & $274(60)$ & 464 \\
\hline
\end{tabular}

The occurrence of measles, mumps, and rubella in subsequent years (1994-2004) is shown in Table 1. There were a few sporadic cases of mumps between 1994 and 1999. Suddenly in 2000 , there were 650 cases, which occurred predominantly among the age group 25-44 and among males than females (Table 2). This pattern continued in 2001, 2002, and 2003. There were no reported cases in 2004 (Fig. 1) (small number of cases between 1 and 5 not captured in the figure). Other vaccine-preventable diseases, i.e., neonatal tetanus, tetanus, pertussis, and diphtheria, have not occurred in Trinidad in the past 25 years. Polio is now eradicated from Trinidad as we partner with the rest of the world in efforts to achieve global eradication.

Public health over the past 100 years has had enormous triumphs in the field of infectious disease control, as illustrated by the elimination of hookworm, smallpox, malaria, cholera, typhoid, yellow fever, and the vaccine-preventable diseases such as measles, mumps, rubella, poliomyelitis, diphtheria, tetanus, and pertussis. The reduced burden of these infectious diseases, which were rampant during 1930-1950, can be attributed mainly to socioeconomic and $\mathrm{PH}$ interventions such as sanitation, water and food safety and improved nutrition, and living standards, all of which are standard public health practices.

In the last 50 years between 1950 and 2000, IMR was reduced by $80 \%$, falling from 69.9 to 13.1 per 1000 live births. Over the same period, standardized mortality ratio also declined from 16.4 to 3.8 per 1000 population. Life expectancy increased from 56.3 to 68.2 for men and 58.5 to 73.6 for women. This is against a background in which GDP per capita rose from 407.8 (USD) to 19,800 (USD).

Globally, life expectancy doubled during the twentieth century (Riley 2005), largely as a result of reductions in child mortality attributable to expanded immunization coverage, clean water, sanitation, and other child-survival programs (Fenner et al. 1988). During the period 1960-2014, life expectancy in Trinidad increased among women from 64.3 to 74 years and 61 to 65 years in men; this gain can in part be attributed to public health interventions.

The epidemiologic transition from infectious diseases to chronic noncommunicable diseases (CND) in Trinidad and Tobago occurred as early as 1947 Mungrue (2012). The rising burden of CND particularly diabetes, hypertension, obesity, cancer, and injuries poses a challenge for all public health systems and requires innovative 
Health Services at
the Primary Care Level,

Fig. 1 Number of cases of mumps reported by year since the start of the mass vaccination strategy

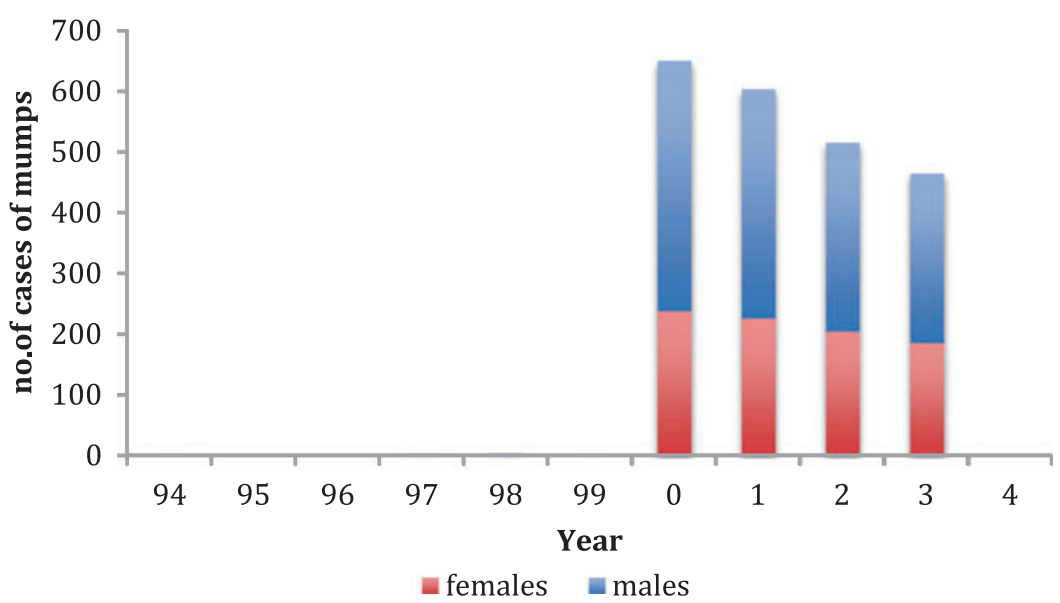

approaches to effectively improve population health. Tobacco use alone kills more than 5.4 million people per year - more deaths than HIV, tuberculosis, and malaria combined - and nearly $80 \%$ of these deaths occur in low- and middleincome countries [51]. If left unchecked, it is estimated to rise to eight million per year by 2030. Hypertension is the only condition that kills more people globally than tobacco use - more than nine million per year. CND pose a particular challenge to public health systems because of their multifactorial nature and the strong links to lifestyle-related factors such as smoking, diet, alcohol use, and physical inactivity, some of which arise from global environment. In the words of Richard Coker, "globalisation, inequality, migration, ecological shifts - these are the challenges facing public health today". No isolated institution can confront these massive societal forces; it will require a global response. Hence, the current core operations of traditional public health functions have become too narrow for this challenge. Public health must now engage with the broader spectrum of social, political, and economic foundations that determine population health.

\section{Conclusion}

In conclusion much has been achieved over the past 100 years. A better understanding of diseases and scientific discoveries such as vaccines, penicillin, and streptomycin led to dramatic decline in both the morbidity and mortality of many diseases in Trinidad. The ambitious goal is to end the epidemic of HIV/AIDS by 2030 through the 90-90-90 strategy - i.e., $90 \%$ of HIV-infected individuals diagnosed, 90\% diagnosed being treated, and 90\% treated achieving viral suppression set by UNAIDS [53]. The resurgence of TB and drug-resistant tuberculosis (DRTP), the persistence of dengue fever, and the new challenges in chikungunya, ebola, and zika, severe acute respiratory syndrome (SARS), and Methicillin-resistant Staphylococcus aureus (MRSA) underscore the need for every country to have core public health functionality to identify a threat when it emerges, stop it promptly, and prevent it wherever possible. This requires highly trained and skilled public health professionals in epidemiology, laboratory sciences, logistics, disease surveillance systems, and rapid response teams with an enabling technological environment. In addition the strengthening of the global response capacity, establishing best practices and supporting research and development will also be needed.

\section{Cross-References}

- Group norms and behaviours

- Public Policy and Public Service

- Public Sevice motivation 


\section{References}

Ali Z, Hull B, Lewis M (1986) Neonatal manifestation of congenital rubella following an outbreak in Trinidad. J Trop Pediatr 32:79-82

Auguste AJ, Lemey P, Pybus OG, Suchard MA, Salas RA, Adesiyun AA, Barrett AD, Tesh RB, Weaver SC, Carrington CV (2010 Oct) Yellow fever virus maintenance in Trinidad and its dispersal through the Americas. J Virol 84(19):9967-9977

Chadee DD, Le Maitre A, Tilluckdharry CC (1992) An outbreak of Plasmodium vivax malaria in Trinidad, W.I. Ann Trop Med Parasitol 86(6):583-590

Chadee DD, Beier JC, Doon R (1999) Re-emergence of Plasmodium malariae in Trinidad. West Indies Ann Trop Med Parasitol 93(5):467-475

Fenner F, Henderson DA, Arita L, Jezek Z, Ladnyi ID (1988) Smallpox and its eradication. World Health Organization, Geneva

Horton R (2016) Offline: public health-when ideology trumps science. The Lancet 388:10053, e11. doi: http:// dx.doi.org/10.1016/S0140-6736(16)31794-9

Hospedalas J, Holder Y, Deyalsingh I, Paul R, Rosenbaum J (1993) Private sector response against the cholera threat in Trinidad and Tobago. Bull Pan Am Health Organ 27(4):331-336

Monath TP (1989) Yellow fever. In: Monath TP (ed) The arboviruses: ecology and epidemiology. CRC Press, Boca Raton, pp 139-231
Mungrue K (2010) The history of the only Rabies epidemic in Trinidad and Tobago 1923-1937. History in Action 1(1). Online: uwispace.sta.uwi.edu

Mungrue K (2012) The changing face of death in Trinidad and Tobago, before and after independence. WIMJ 61(4):452-459

Orenstein WA, Preblud SR, Bart KJ, Hinman AR (1985) Methods of assessing the impact of congenital rubella infection. Rev Infect Dis 7(suppl 1):522-528

Pan American Health Organization (1991) Cholera situation in the Americas: an update. Epidemiol Bull 12(4):43

Pawan JL (1936) Transmission of paralytic rabies in Trinidad by the vampire bat: Desmodus rotundus murinus, Wagner, 1840. Ann Trop Med Parasitol 30(1):101-129

Riley JC (2005) Estimates of regional and global life expectancy, 1800-2001. Popul Dev Rev 31:537-543

Rosen G (1958) A history of public health. MD Publications, New York

Tikasingh E, Chadee DD, Rawlins S (2011) The control of hookworm disease in Commonwealth Caribbean countries. Acta Trop 120:24-30

Tuberculosis in the region of the Americas. Regional Report (2011) Epidemiology. Control and Financing, PAHO/WHO www.paho.org

WHO Report on the Global Tobacco Epidemic (2008) The MPOWER package. WHO, Geneva. ISBN:978 924 1596282

World Health Organization (1980) Declaration of global eradication of smallpox. Wkly Epidemiol Rec 55:145-152 